\title{
Growth Charts for Children With Down Syndrome in the United States
}

Babette S. Zemel, PhD ${ }^{a, b}$, Mary Pipan, MD ${ }^{b, c}$, Virginia A. Stallings, MD ${ }^{a, b}$, Waynitra Hall, MS ${ }^{a}$, Kim Schadt, MSN ${ }^{b, c}$, David S. Freedman, PhD ${ }^{d}$, Phoebe Thorpe, MD, MPH

BACKGROUND AND OBJECTIVES: Children with Down syndrome (DS) have lower birth weights and grow more slowly than children without DS. Advances in and increased access to medical care have improved the health and well-being of individuals with DS; however, it is unknown whether their growth has also improved. Our objective was to develop new growth charts for children with DS and compare them to older charts from the United States and more contemporary charts from the United Kingdom.

METHODS: The Down Syndrome Growing Up Study (DSGS) enrolled a convenience sample of children with DS up to 20 years of age and followed them longitudinally. Growth parameters were measured by research anthropometrists. Sex-specific growth charts were generated for the age ranges birth to 36 months and 2 to 20 years using the LMS method. Weight-for-length and BMI charts were also generated. Comparisons with other curves were presented graphically.

RESULTS: New DSGS growth charts were developed by using 1520 measurements on 637 participants. DSGS growth charts for children $<36$ months of age showed marked improvements in weight compared with older US charts. DSGS charts for 2- to 20-year-olds showed that contemporary males are taller than previous charts showed. Generally, the DSGS growth charts are similar to the UK charts.

concLusions: The DSGS growth charts can be used as screening tools to assess growth and nutritional status and to provide indications of how growth of an individual child compares with peers of the same age and sex with DS.

WHAT'S KNOWN ON THIS SUBJECT: Children with Down syndrome (DS) grow differently from other children. Advances in medical care, access to care, and improved life expectancy suggest that contemporary growth patterns may have improved over recent decades for children with DS in the United States.

WHAT THIS STUDY ADDS: New growth charts are presented for length/height, weight, head circumference, and BMI for children with DS (birth to $20 \mathrm{y}$ ). Weight gain in children $<36$ months, and stature for males are improved compared with older growth charts.
Divisions of ${ }^{a}$ Gastroenterology, Hepatology, and Nutrition, and ${ }^{c}$ Behavioral Pediatrics, The Children's Hospital of Philadelphia, Philadelphia Pennsylvania; ${ }^{b}$ Department of Pediatrics, The University of Pennsylvania Perelman School of Medicine, Philadelphia, Pennsylvania; and Divisions of ${ }^{d}$ Nutrition, Physical Activity, and Obesity, and ${ }^{e}$ Birth Defects and Developmental Disabilities, Centers for Disease Control and Prevention, Atlanta, Georgia

Dr Zemel conceptualized and designed the study, analyzed the data, and drafted the initial manuscript; Dr Pipan participated in conceptualization and design of the study, participant recruitment, and review of analyses and revised the manuscript; Dr Stallings participated in conceptualization and design of the study and review of analyses and revised the manuscript; Ms Hall and Ms Kim Schadt participated in study design and implementation, participant recruitment, and data collection and revised the manuscript; Drs Freedman and Thorpe critically reviewed the analyses and revised the manuscript; and all authors approved the final manuscript as submitted

The findings and conclusions in this report are those of the authors and do not necessarily represent the official position of the Centers for Disease Control and Prevention.

www.pediatrics.org/cgi/doi/10.1542/peds.2015-1652

DOI: 10.1542/peds.2015-1652

Accepted for publication Aug 19, 2015

Address correspondence to Babette S. Zemel, PhD, Division of Gastroenterology, Hepatology and Nutrition, The Children's Hospital of Philadelphia, 3535 Market St, Room 1560, Philadelphia, PA 19104-4399. E-mail: zemel@email.chop.edu

PEDIATRICS (ISSN Numbers: Print, 0031-4005; Online, 1098-4275).

Copyright (C) 2015 by the American Academy of Pediatrics 
Down syndrome (DS) occurs in $\sim 1$ in 700 births in the United States ${ }^{1}$ and is associated with a spectrum of physical and cognitive disabilities. In 1988, growth charts for US children with DS were published by using data from multiple centers collected before 1988,2 showing slow growth and short stature of children with DS. Since 1988, much has changed in the care of children with DS, and the applicability of those charts to growth in contemporary children with DS has been questioned. ${ }^{3,4}$ Currently, the American Academy of Pediatrics recommends using standard growth charts for evaluating children with DS until such time as current DS-specific charts are available. ${ }^{3}$

Advances in medical care, and increased access to care, have improved health and well-being of individuals with DS in the United States such that life expectancy has risen from 35 years in $1982^{5}$ to 53 years in 2007.6 One would expect that growth of contemporary children with DS has also improved, and thus previous growth charts would lack reliability. In Europe, growth charts for children with DS used more recent data extracted from medical chart review, ${ }^{7,8}$ most notably in the United Kingdom and Ireland. ${ }^{9}$ To address concerns that growth of contemporary US children with DS is not adequately characterized by the 1988 charts, the Down Syndrome Growing Up Study (DSGS), as a cooperative project with the Centers for Disease Control and Prevention (CDC), developed growth curves based on systematically obtained growth measurements and modern statistical techniques for developing reference percentiles. We present these growth curves, characterize trends in growth of children with DS living in the United States over the past few decades, and offer comparisons with the UK growth charts $^{9}$ to assess international differences in growth of children with DS.

\section{METHODS}

Children with DS, from birth to 20 years of age, were recruited from the Trisomy 21 Clinic at The Children's Hospital of Philadelphia (CHOP), CHOP general pediatric practices, parent interest groups, community events, and schools, mainly in the greater Philadelphia area. Children were ineligible if they had other major genetic disorders known to affect growth (eg, sickle cell disease) or were not in a usual state of health (eg, cancer therapy) at the time of measurement. Enrollment occurred from January 18, 2010, to July 23, 2013. Follow-up measurements occurred every 3 months for age $<12$ months, every 6 months for ages 12 to 36 months, and annually if age $>36$ months until data collection closed. Most evaluations occurred at the CHOP Clinical and Translational Research Center (43\%) or Pediatric and Adolescent Specialty Care Centers (47\%). The remaining study visits took place at community locations $(10 \%)$ in Maryland, Virginia, New York, and Texas (National Down Syndrome Congress).

After written informed consent was obtained, children underwent an anthropometric examination. Head circumference (to nearest $0.1 \mathrm{~cm}$ ) was measured with a nonstretchable tape measure. Weight was measured on an electronic digital scale in light clothing for older children (to nearest $0.1 \mathrm{~kg}$ ) and without clothing or diapers for infants and toddlers (to nearest $0.01 \mathrm{~kg}$ ). Length

(to nearest $0.1 \mathrm{~cm}$ ) was measured on an infant lengthboard for infants and toddlers unable to stand unsupported. For all others, height (to nearest $0.1 \mathrm{~cm}$ ) was measured with a stadiometer. Trained personnel obtained measurements following standardized techniques. ${ }^{10}$

Measurements taken at CHOP locations used standard equipment monitored by the bioengineering department. At community locations, length and stature measurements were obtained using a portable lengthboard/stadiometer (Shorr board, Shorr Productions, Olney, MD) and a portable digital electronic scale (Scaletronix, White Plains, NY).

Parents completed questionnaires providing demographic, medical history, and puberty status ${ }^{11}$ information.

The study was approved by the Committee for the Protection of Human Subjects of CHOP.

\section{Data Analysis}

Data were stored in research electronic data capture (REDCap) ${ }^{12}$ and analyzed by using Stata 12.0 (Stata Corp, College Station, TX). Means and frequencies were generated, as appropriate, for all data. Growth measurements were compared with the CDC (ages 2-20 years) and World Health Organization (WHO) (ages birth-36 months) growth charts, ${ }^{13,14}$ and $z$ scores (SD scores) were calculated to compare the growth of children with DS to standard charts.

Growth charts were created by using the LMS Chartmaker version 1.16 (Harlow Printing, South Shields, UK), ${ }^{15,16}$ as described by Cole and Green. ${ }^{17}$ This method uses the Box-Cox transformation to account for skewness, and a maximum penalized likelihood method to estimate smoothed values for $L(\lambda)$, $\mathrm{M}$ (median), and $\mathrm{S}$ (coefficient of variation) over the age range. These values are used to calculate centile curves using the following equation: Centile $=M(1+L S Z)^{1 / L}$,

where $\mathrm{L}, \mathrm{M}$, and $\mathrm{S}$ are age-specific values, and $\mathrm{Z}$ is the value of a given percentile in the cumulative standard normal distribution. For example, for $\mathrm{Z}=0$, the 50 th centile can be estimated, and for $Z=-1.64$, the fifth percentile can be calculated. Exact $z$ scores are calculated by using the following equation:

$Z=\left[(X / M)^{L}-1\right] / L S$, where $X$ is the measured value for an individual. The goodness of fit of 
the centile curves was assessed by using visual inspection and q-q plots comparing the observed data to that generated using the estimated parameters.

To be consistent with criteria used in developing the CDC 2000 growth charts ${ }^{13}$ for children $<3$ years, very low birth weight $(<1500 \mathrm{~g})$ children were excluded; for children born 34 to 37 weeks' gestation, chronological age was adjusted for gestational age; and it was assumed that length was $0.7 \mathrm{~cm}$ greater than standing height. Reported birth weight was included in the development of the weight-for-age charts. For children with DS $>2$ years of age unable to stand without assistance, length was measured, and the values were adjusted to be equivalent to stature measures. Measurements of participants $>21$ years who continued in the study were included in the analyses to provide stability for the curves near the age of growth cessation. However, final curves were truncated at age 20 years. Sex-specific curves were generated for weight and height/length for ages birth to 20 years. Head circumference curves were created separately for ages birth to 3 years and 2 to 20 years of age to achieve an optimal curve fit. Weight-for-length curves were created for children $<3$ years of age, and BMI curves were created for children 2 to 20 years of age.

The curves for weight and length/ height were compared graphically to the 1988 growth curves for the United States by Cronk et $\mathrm{al}^{2,18}$ and 2002 curves for the United Kingdom by Styles et al. ${ }^{9}$

Baseline differences between those with one versus multiple visits were compared by $t$ tests and $\chi^{2}$ tests as appropriate. Differences in growth between ethnic groups were compared using mixed-effects regression models accounting for multiple observations per subject. The LMS method assumes independent observations. Therefore, to evaluate the effect of multiple observations per subject, growth curves using a single observation per subject were created and found to be similar to the longitudinal DSGS curves (Supplemental Fig 3).

\section{RESULTS}

The study enrolled 637 participants from 25 states; $86 \%$ were from Pennsylvania and New Jersey. A total of 1520 growth measurements were acquired. The average number of visits per participant was 3 (range 1-9). Participants with only 1 visit were older $(12 \pm 6$ years [mean $\pm \mathrm{SD}$ ] $n=234$ ) at baseline than those with multiple visits ( $7 \pm 6$ years, $n=403$ ), but there were no meaningful differences by sex or race/ethnicity between those with 1 versus $>1$ visit. The sample was $51 \%$ male, $9 \%$ Hispanic, 11\% non-Hispanic black (African American), and 73\% non-Hispanic white by self-report. Twenty-one percent of subjects were born premature (gestational age $<37$ weeks), and $7 \%$ were born $<34$ weeks' gestation (Supplemental Table 3). The average reported birth weight of all participants was $2.97 \pm$ $0.62 \mathrm{~kg}$. Nine subjects with a birth weight $<1500$ g were excluded. Supplemental Table 3 shows the prevalence of selected common comorbidities in children with DS as reported by parents. Cardiac defects affected $53 \%$ of the sample, and thyroid disease affected $23 \%$ of participants.

Table 1 provides descriptive statistics for growth outcomes and $z$ scores relative to WHO growth charts ${ }^{14}$ for children $<3$ years of age and CDC 2000 growth charts ${ }^{19}$ for the 2 - to 20-year age range. Children with DS were shorter with smaller head circumference for age (low $z$ scores) compared with reference charts. Deficits in weight-for-age were more modest. Weight-for-length $z$ scores for children with DS $<3$ years were similar to the distribution of the
WHO charts, ${ }^{14}$ but the mean BMI $z$ score for children with DS aged 2 to 20 years was higher.

Supplemental Tables 4 through 19 provide the sex- and age-specific $\mathrm{L}, \mathrm{M}$, and $S$ values and selected centiles for weight, length/height, weight-forlength, BMI and head circumference used to calculate $z$ scores and percentiles. To assist in these complex calculations, a Web site calculator is available (http://www. research.chop.edu/web/zscore). Corresponding growth charts are provided in Supplemental Figs 4 to 11 .

The new DSGS length/height and weight curves were compared with the Cronk $1988^{2}$ US and Styles ${ }^{9} 2002$ UK curves (Figs 1 and 2). Both the DSGS and UK 2002 curves show an improvement in weight gain in the first 3 years of life (Fig $1 \mathrm{~A}$ and $\mathrm{B}$ ) compared with the US 1988 curves. Length of girls birth to 3 years is quite similar for all 3 sets of curves (Fig 1D). Contemporary US boys have slightly greater lengths than those in the other studies (Fig 1C).

The DSGS weight curves for ages 2 to 20 years (Fig $2 \mathrm{~A}$ and $\mathrm{B}$ ) approximate the US 1988 weight curves at many ages, ${ }^{2}$ especially for the fifth and 50th percentiles. Compared with the US 1988 weight curves, the 95th percentile of older girls ( $>8$ years) and the fifth and 50th percentiles for older boys ( $\geq 12$ years) are greater, yet the 95th percentile for boys is lower than the corresponding percentiles on the DSGS curves. The 95th percentile for weight of DSGS children is greater than the 95th percentile for the United Kingdom, especially for older boys.

For 2 to 18 year olds, DSGS boys are taller than the 1988 US curves at most ages (Fig 2C). At age 18 years (the oldest age in the 1988 US curves), the tallest boys (95th percentile) in the DSGS curves are notably taller than the tallest boys in the US 1988 curves. DSGS girls are transiently taller than US 1988 girls 
TABLE 1 Growth Characteristics (Mean and SD) of Children With Down Syndrome With z Scores Based on the $\mathrm{CDC}^{13}$ and $\mathrm{WHO}^{14}$ Standard Growth Charts

\begin{tabular}{|c|c|c|c|c|c|c|c|c|}
\hline \multirow[t]{2}{*}{ Variable } & \multicolumn{4}{|c|}{ Age Birth to $3 \mathrm{y}$} & \multicolumn{4}{|c|}{ Age 2 to $20 \mathrm{y}$} \\
\hline & $n$ & No. Obs & Mean & SD & $n$ & No. Obs & Mean & SD \\
\hline Age, y & 162 & 539 & 1.4 & 0.8 & 553 & 1083 & 9.4 & 5.2 \\
\hline Height/length, cm & 162 & 538 & 73.6 & 8.9 & 512 & 979 & 123.8 & 23.4 \\
\hline WH0/CDC $z$ score ${ }^{a}$ & & & -1.7 & 1.2 & 510 & 972 & -2.1 & 1.1 \\
\hline Wt, kg & 162 & 539 & 9.3 & 2.4 & 552 & 1081 & 33.2 & 20.4 \\
\hline WHO/CDC $z$ score ${ }^{a}$ & & & -0.8 & 1.2 & 552 & 1081 & -0.5 & 1.3 \\
\hline Head circumference, $\mathrm{cm}$ & 162 & 536 & 43.7 & 2.7 & 541 & 1055 & 49.2 & 2.8 \\
\hline WHO z score ${ }^{b}$ & & & -1.6 & 1.0 & 59 & 289 & -1.9 & 1.0 \\
\hline Weight for length $z$ score ${ }^{a}$ & 162 & 538 & 0.2 & 1.1 & & & & \\
\hline $\mathrm{BMl}, \mathrm{kg} / \mathrm{m}^{2}$ & & & & & 512 & 979 & 21.1 & 5.8 \\
\hline CDC BMl $z$ score ${ }^{a}$ & & & & & 512 & 979 & 0.9 & 1.0 \\
\hline
\end{tabular}

No. Obs: number of observations.

a $Z$ scores calculated using standard WHO growth charts for age birth to $3 y^{14}$ and the CDC growth charts for ages 2 to 20 y. 13

b $z$ score calculated using standard WHO growth charts for birth to $5 \mathrm{y}$. around the ages of early to mid puberty, but with no appreciable difference in final height (Fig 2D). Overall, the new DSGS curves for length and height are similar to the UK 2002 curves, although
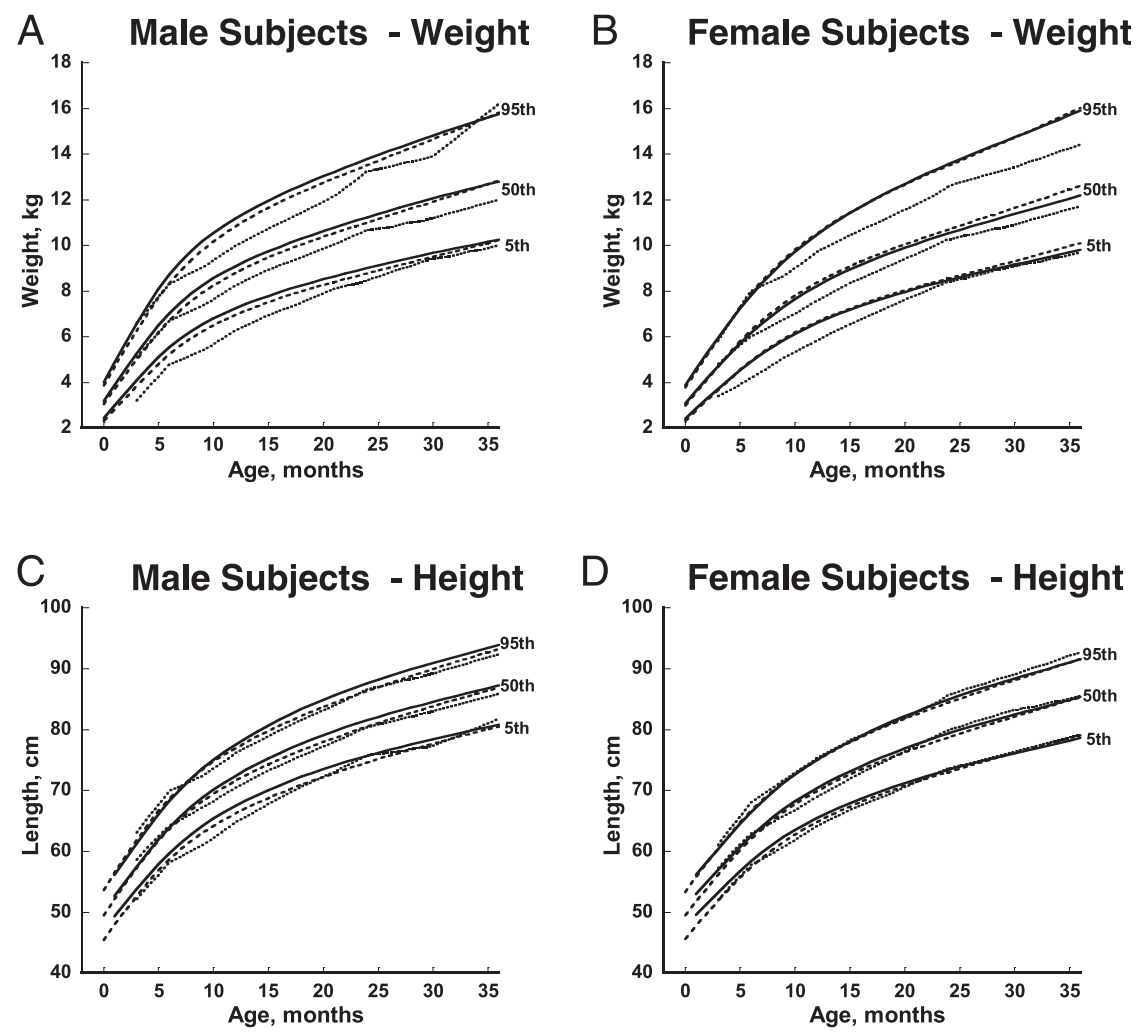

\section{FIGURE 1}

Curve comparisons for weight in kilograms and length in centimeters for male and female subjects, birth to 36 months of age. Contemporary curves from the DSGS (solid line) are compared with those from the US 1988 curves from Cronk et al (dotted line) and the UK 2002 curves from Styles et al (dashed line).
The current study developed curves for weight-for-length for birth to 3 years (Supplemental Fig 10), BMI for 2 to 20 years (Supplemental Fig 11), and head circumferences for younger and older children (Supplemental Figs 6 and 9). Because no previously published data on these values were available, examination of secular trends was not possible.

DSGS $z$ scores for growth outcomes were calculated and compared among non-Hispanic blacks, Hispanics, and non-Hispanic whites (Table 2). Non-Hispanic blacks had significantly greater $z$ scores for weight, length (or height), and BMI, and Hispanics had significantly greater $z$ scores for weight, BMI, and weight-for-length, compared with non-Hispanic whites. Although these comparisons reflect the variability between the mean $z$ values among racial/ethnic groups, they do not address the extra variability that arises from the estimations of the $z$ values themselves.

\section{DISCUSSION}

This study describes the growth of a convenience sample of contemporary children with DS in their usual state of health living in the United States. The characteristic short stature, small head circumference, and normal to high relative weight measures (weight-for-length and BMI) associated with this genetic syndrome are evident. These growth charts are designed to be used as screening tools to assess growth and nutritional status and provide indications of how the growth of an individual child compares with peers of the same age and sex with DS.

Marked improvements in weight status for the first 36 months of life are evident from comparisons with previously published US reference ranges. For children aged 2 to 20 years, the weight distribution is approximately similar to those published more than 25 years ago, with 2 exceptions: the 95th percentile 


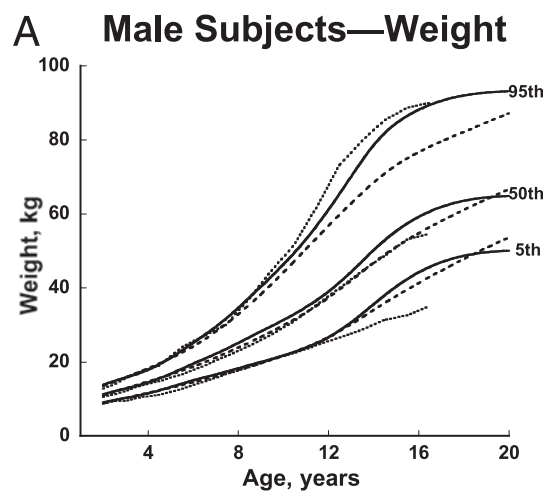

C Male Subjects-Height

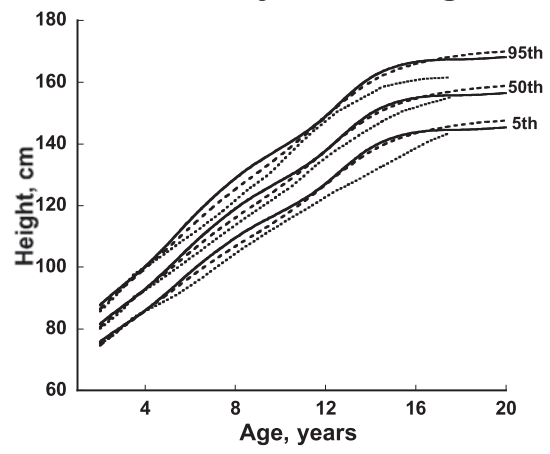

FIGURE 2

Curve comparisons for weight in kilograms and height in centimeters for male and female subjects, 2 to 20 years of age. Contemporary curves from the DSGS (solid line) are compared with those from the US 1988 curves from Cronk et al (dotted line) and the UK 2002 curves from Styles et al (dashed line).

for girls is greater than the US 1988 95th percentile ${ }^{2}$ for age $\geq 8$ years, and for boys $\geq 12$ years, the fifth and 50th percentiles are greater, yet the 95th percentile is lower (beginning approximately age 8 years) than the corresponding US 1988 percentiles. Given the increasing prevalence of pediatric obesity in the general population during this time period, ${ }^{20}$ it is surprising that greater shifts in
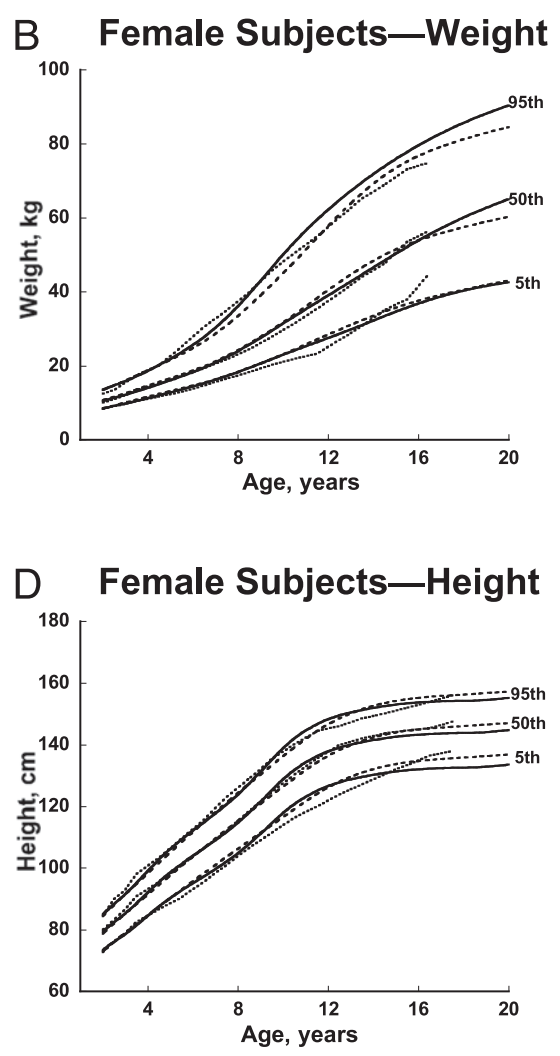

---- US 1988

the weight-for-age distribution did not occur.

Changes in linear growth over the past few decades have mainly occurred in males. Boys, birth to 3 years, have modestly longer length than previously estimated. The fifth, 50th, and 95th percentiles are greater than previous corresponding percentiles at most ages after approximately age 5 years, and the 95th percentile for boys is greater than the older growth curves. The explanation for this secular trend in boys but not girls is unclear. Sex differences in health complications of DS may possibly contribute to this pattern. For example, Freeman et al reported a higher preponderance of female infants with DS who had atrioventricular septal defects. ${ }^{21}$ Alternatively, short stature among girls may be more acceptable to parents and physicians than among boys, as reported among children without DS, ${ }^{22}$ leading to less investigation and intervention. However, the strong consistency in US and UK weight and length/stature distributions suggests that these curves represent growth patterns of well-nourished contemporary children with DS with access to current medical care practices.

Feeding difficulties are common for infants with DS and may be due to hypotonia; poor oromotor, pharyngeal, and esophageal coordination; fatigue; difficulty initiating sucking; slow sucking reflex; vomiting; and choking. ${ }^{23}$ Nutritional status in the early years is particularly concerning. We present weight-for-length charts for children birth to 3 years to aid in nutritional screening for growth faltering, wasting and excess weight gain during this critical period of brain development.

We present the first BMI charts for US children with DS, aged 2 to 20 years. Children with DS have shorter limbs than children without DS, resulting in

TABLE 2 Differences Among Race/Ethnicity Groups In Growth Outcomes

\begin{tabular}{|c|c|c|c|c|c|c|c|c|c|c|c|c|}
\hline \multirow[t]{2}{*}{ DSGS z scores } & \multicolumn{3}{|c|}{ Non-Hispanic White } & \multicolumn{3}{|c|}{ Non-Hispanic Black } & \multicolumn{3}{|c|}{ Hispanic } & \multicolumn{3}{|c|}{ Other ${ }^{a}$} \\
\hline & Mean \pm SD & No. Obs & $\mathrm{n}$ & Mean $\pm S D$ & No. Obs & $\mathrm{n}$ & Mean \pm SD & No. Obs & $n$ & Mean \pm SD & No. Obs & $n$ \\
\hline Wt & $-0.10 \pm 0.93$ & 1093 & 457 & $0.63 \pm 1.07^{\star \star \star}$ & 154 & 70 & $0.25 \pm 0.98^{\star \star}$ & 138 & 58 & $-0.07 \pm 0.94$ & 94 & 36 \\
\hline Length/height & $-0.08 \pm 0.97$ & 1090 & 457 & $0.49 \pm 0.94^{\star \star \star}$ & 154 & 70 & $0.07 \pm 1.13$ & 137 & 58 & $0.14 \pm 0.98$ & 94 & 36 \\
\hline $\mathrm{BMI}^{\mathrm{b}}$ & $-0.07 \pm 0.99$ & 753 & 389 & $0.68 \pm 1.06^{\star \star \star}$ & 93 & 54 & $0.32 \pm 0.83^{\star}$ & 79 & 43 & $0.03 \pm 1.02$ & 55 & 28 \\
\hline Head circumference ${ }^{c}$ & $0.10 \pm 0.99$ & 364 & 106 & $-0.25 \pm 1.06$ & 68 & 25 & $-0.07 \pm 1.06$ & 65 & 22 & $-0.20 \pm 0.72$ & 40 & 12 \\
\hline Weight for length ${ }^{\mathrm{C}}$ & $-0.04 \pm 0.97$ & 366 & 106 & $0.23 \pm 1.24$ & 68 & 25 & $0.42 \pm 0.88^{\star}$ & 63 & 21 & $-0.50 \pm 0.93$ & 40 & 12 \\
\hline
\end{tabular}

All outcomes are expressed as age and sex-specific DSGS z scores. No. Obs: number of observations

a Other includes Asian, Native American, and mixed race. Significantly different from Non-Hispanic White group: ${ }^{\star \star \star} P<.001 ;{ }^{\star \star} P<.01 ;{ }^{\star} P<.05$

b Age $>2$ y.

${ }^{c}$ Age $<3$ y. 
a different distribution of body mass relative to height. Obesity is common in DS ${ }^{24}$; among 1450 adults with developmental disabilities, adults with DS had a higher prevalence than other groups, with $>50 \%$ of adults with DS being obese. ${ }^{25}$ It is unknown whether the use of the CDC 2000 BMI charts ${ }^{19}$ and traditional cutoffs ${ }^{26}$ to define obesity are appropriate given the altered body mass distribution characteristic of DS. Our average BMI values were nearly 1 SD above the median of the CDC charts, compared with 0.5 SD among children examined in recent US surveys. ${ }^{27}$ Excess adiposity is a concern, and thus a screening tool that is appropriate for children with DS is needed. It is important to recognize that the DSGS BMI charts merely describe the distribution of BMI values in this sample. Plotting an individual BMI value on these charts provides information on how an individual compares with other children with DS. The DSGS BMI charts do not represent an ideal healthy distribution of BMI. Additional investigation is required to determine how best to apply the DSGS BMI charts to screen for excess adiposity and associated health outcomes.

Concerns have been raised regarding condition-specific growth charts based on limitations of sample size and its representativeness as well as measurement quality. ${ }^{28}$ This study addressed some concerns by using standardized measurements on $>600$ contemporary children with DS in their usual state of health. We included children with cardiac and thyroid complications, which could affect growth. Reassuringly, the prevalence of these important comorbidities is similar to other studies, ${ }^{29,30}$ suggesting that our sample is similar to the population of children with DS in the United States with respect to these comorbidities.

This study had several limitations. An assumption underlying statistical testing is that the data on which the tests are based represents a random sample from the target population. In this study, a convenience sample of children attending clinics and community events, not a random sample, was used. We do not think that the use of a convenience sample meaningfully biased our results as shown in Supplemental Fig 3, but this should be kept in mind when assessing the results of statistical testing. This sample is mostly from the greater Philadelphia region and may not represent US regional variation in race/ethnicity and in obesity. This study includes non-Hispanic blacks (11\%) and Hispanics (9\%) at lower than national averages (14\%) non-Hispanic black and 23\% Hispanic children (age $<18$ years) based on the 2010 US Census). ${ }^{31}$ For children with DS, the race/ethnicity distribution in the US population is unknown. An 11-state surveillance study found that non-Hispanic black mothers had a lower prevalence ratio (0.77) whereas Hispanic mothers had a higher prevalence ratio (1.12) of DS births compared with non-Hispanic white mothers. ${ }^{32}$ The impact on the DSGS curves of the lower representation of minority groups can be inferred from the comparison of growth $z$ scores among groups. Non-Hispanic black children were taller and heavier, and Hispanic children were heavier than their non-Hispanic white peers. On the basis of these findings, it is possible that the DSGS growth curves underestimate length/height and weight due to the underrepresentation of non-Hispanic blacks and Hispanics.

Because no data were collected from families who declined participation, the effect of recruitment bias cannot be estimated. The effect of multiple observations per subject in this longitudinal convenience sample is also difficult to ascertain. However, sensitivity analyses indicated that the impact of this lack of independence among data points used to estimate the growth curves was negligible.
Lastly, these growth curves are based on a contemporary sample of children in their usual state of health and may not represent "optimal" growth of children with DS.

\section{CONCLUSIONS}

The DSGS growth charts presented here for children with DS residing in the United States are based on a contemporary sample of infants, children, and adolescents in their usual state of health, using standardized measurements, and modern statistical techniques to generate smoothed percentiles. Previously unavailable weight-forlength and BMI charts were also developed to provide additional tools for assessment of nutritional status. The improvements in growth in the past 25 years and consistency with 2002 charts from the United Kingdom provide further evidence of the importance and strengths of these new charts.

\section{ACKNOWLEDGMENTS}

Our greatest thanks go to the children and their families who participated in this study and the parent interest groups, schools, camps, and other organizations that assisted in reaching those families. We also express our appreciation to the Trisomy 21 Clinic and the Adolescent and Pediatric Specialty Care Centers of CHOP, to team members of the DSGS and the Clinical and Translational Research Center, and to Dr Sonja Rasmussen for her efforts early in this process to share her vision and ensure support for this project.

\section{ABBREVIATIONS}

CDC: Centers for Disease Control and Prevention

CHOP: The Children's Hospital of Philadelphia

DS: Down syndrome

DSGS: Down Syndrome Growing Up Study

WHO: World Health Organization 
FINANCIAL DISCLOSURE: The authors have indicated they have no financial relationships relevant to this article to disclose.

FUNDING: Supported by U01 DD000518, UL1RR024134 (National Center for Research Resources), and UL1TR000003 (National Center for Advancing Translational Sciences)

POTENTIAL CONFLICT OF INTEREST: The authors have indicated they have no potential conflicts of interest to disclose.

\section{REFERENCES}

1. Parker SE, Mai CT, Canfield MA, et al; National Birth Defects Prevention Network. Updated National Birth Prevalence estimates for selected birth defects in the United States, 2004-2006. Birth Defects Res A Clin Mol Teratol. 2010;88(12):1008-1016

2. Cronk C, Crocker AC, Pueschel SM, et al Growth charts for children with Down syndrome: 1 month to 18 years of age. Pediatrics. 1988;81(1):102-110

3. Bull MJ; Committee on Genetics. Health supervision for children with Down syndrome. Pediatrics. 2011;128(2): 393-406

4. Rasmussen SA, Whitehead N, Collier SA, Frías JL. Setting a public health research agenda for Down syndrome: summary of a meeting sponsored by the Centers for Disease Control and Prevention and the National Down Syndrome Society. Am J Med Genet A. 2008; 146A(23):2998-3010

5. Thase ME. Longevity and mortality in Down's syndrome. J Ment Defic Res. 1982;26 (pt 3):177-192

6. Presson AP, Partyka G, Jensen KM, et al Current estimate of Down syndrome population prevalence in the United States. J Pediatr. 2013;163(4):1163-1168

7. Myrelid A, Gustafsson J, Ollars B, Annerén G. Growth charts for Down's syndrome from birth to 18 years of age. Arch Dis Child. 2002;87(2):97-103

8. Van Gameren-0osterom HB, Van Dommelen P, Oudesluys-Murphy AM, Buitendijk SE, Van Buuren S, Van Wouwe JP. Healthy growth in children with Down syndrome. PLoS One. 2012;7(2): e31079

9. Styles ME, Cole TJ, Dennis J, Preece MA. New cross sectional stature, weight, and head circumference references for Down's syndrome in the UK and Republic of Ireland. Arch Dis Child. 2002;87(2): 104-108

10. Lohman T, Roche AF, Martorell R. Anthropometric standardization reference manual. Champaign, IL: Human Kinetics Books; 1988

11. Morris NM, Udry JR. Validation of a selfadministered instrument to assess stage of adolescent development. $J$ Youth Adolesc. 1980;9(3):271-280

12. Harris PA, Taylor R, Thielke R, Payne J, Gonzalez N, Conde JG. Research electronic data capture (REDCap) a metadata-driven methodology and workflow process for providing translational research informatics support. J Biomed Inform. 2009;42(2): 377-381

13. Kuczmarski RJ, Ogden CL, Guo SS, et al. 2000 CDC Growth Charts for the United States: methods and development. Vital Health Stat. 2002;May11(246):1-190

14. WHO Multicentre Growth Reference Study Group. WHO Child Growth Standards: head circumference-for-age, arm circumference-for-age, triceps skinfold-for-age and subscapular skinfold-for-age: methods and development. Geneva, Switzerland: World Health Organization; 2007

15. Pan H, Cole T. LMSchartmaker, a program to construct growth reference data using the LMS method, Software Version 2.43. 2010. Available at http://www.healthforallchildren.com/? product=Imschartmaker-pro

16. Pan H, Cole TJ. LMSgrowth, a Microsoft Excel add-in to access growth references based on the I method, Version 2.69 2010. Available at: http://www. healthforallchildren.com/shop-base/ software/Imsgrowth

17. Cole TJ, Green PJ. Smoothing reference centile curves: the LMS method and penalized likelihood. Stat Med. 1992; 11(10):1305-1319

18. Cronk CE. Growth of children with Down's syndrome: birth to age 3 years. Pediatrics. 1978;61(4):564-568

19. Ogden CL, Kuczmarski RJ, Flegal KM, et al. Centers for Disease Control and Prevention 2000 growth charts for the
United States: improvements to the 1977 National Center for Health Statistics version. Pediatrics. 2002;109(1):45-60

20. Ogden CL, Carroll MD, Kit BK, Flegal KM. Prevalence of obesity in the United States, 2009-2010. NCHS Data Brief no. 82. Hyattsville, MD: National Center for Health Statistics; 2012:1-8

21. Freeman SB, Bean LH, Allen EG, et al. Ethnicity, sex, and the incidence of congenital heart defects: a report from the National Down Syndrome Project. Genet Med. 2008;10(3): 173-180

22. Grimberg A, Feemster KA, Pati S, et al. Medically underserved girls receive less evaluation for short stature. Pediatrics. 2011;127(4):696-702

23. Lewis E, Kritzinger A. Parental experiences of feeding problems in their infants with Down syndrome. Downs Syndr Res Pract. 2004;9(2):45-52

24. Roizen NJ, Patterson D. Down's syndrome. Lancet. 2003;361(9365): 1281-1289

25. Hsieh K, Rimmer JH, Heller T. Obesity and associated factors in adults with intellectual disability. J Intellect Disabil Res. 2014;58(9):851-863

26. Krebs NF, Himes JH, Jacobson D, Nicklas TA, Guilday P, Styne D. Assessment of child and adolescent overweight and obesity. Pediatrics. 2007;120(suppl 4): S193-S228

27. Weber DR, Leonard MB, Shults J, Zemel BS. A comparison of fat and lean body mass index to BMl for the identification of metabolic syndrome in children and adolescents. J Clin Endocrinol Metab. 2014;99(9): 3208-3216

28. U.S. Department of Health and Human Services, Health Resources and Services Administration, Maternal and Child Health. The CDC growth charts for children with special health care needs. Issues regarding the use of condition-specific growth charts. 
Available at: http://depts.washington. edu/growth/cshcn/text/page6b.htm. Accessed March 20, 2015

29. Morris JK, Garne E, Wellesley D, et al. Major congenital anomalies in babies born with Down syndrome: a EUROCAT population-based registry study. Am J Med Genet A. 2014;164A(12): 2979-2986
30. Roizen NJ, Magyar Cl, Kuschner ES, et al. A community cross-sectional survey of medical problems in 440 children with Down syndrome in New York State. $J$ Pediatr. 2014;164(4):871-875

31. Humes KR, Jones NA, Ramirez RR. Overview of Race and Hispanic Origin: 2010. United States Census Bureau; March 2011. Available at: www.census. gov/prod/cen2010/briefs/c2010br-02.pdf. Accessed December 4, 2014

32. Canfield MA, Honein MA, Yuskiv N, et al. National estimates and race/ ethnic-specific variation of selected birth defects in the United States, 1999-2001. Birth Defects Res A Clin Mol Teratol. 2006;76(11): 747-756 